\title{
ZnO AND ZnO/PbS HETEROJUNCTION PHOTO ELECTROCHEMICAL CELLS
}

\author{
Bachu Naveen Kumar ${ }^{1}$ \\ ${ }^{I}$ Master of technology in nanotechnology, Department of Electronics \& Communication, NIT Agartala, India
}

\begin{abstract}
Photo Electrochemical Cell (PEC) can also be used for splitting of water into hydrogen and Oxygen. Here, ZnO nanorod PEC has been prepared in hydrothermal method and $\mathrm{ZnO} / \mathrm{PbS}$ quantum dot PEC has been prepared by hydrothermal method and chemical bath deposition method. UV-Visible spectroscopy has been observed. Flat band voltage, bandwidth and majority charge carriers have been calculated from Mott-Schottky. Impedance variation at semiconductor and electrolyte junction has been observed with Electrochemical Impedance Spectroscopy (EIS).
\end{abstract}

Keywords: Hydrothermal, Chemical bath, ZnO/PbS, UV-Vis, Mott-Schottky, EIS.

\section{INTRODUCTION}

Semiconductor junction plays pivotal role in PEC for generation of charge carriers. Generated charge carriers are used to split water molecule into hydrogen and oxygen gases [4]. The splitting rate of water molecule depends upon generation rate of charge carriers which depends on solar efficiency related factors. Proper utilization of solar spectrum also increases solar efficiency. Increase in solar efficiency in turn increases carrier generation rate. Maximum amount of solar spectrum spreads in UV and Visible regions [1]. $\mathrm{ZnO}$ is a metal oxide semiconductor having very high energy band gap of 3.2 to $3.4 \mathrm{eV}$. So that Zinc Oxide $(\mathrm{ZnO})$ can absorb solar spectrum approximately at $387 \mathrm{~nm}$ which is in UV region [6]. Lead sulfide $(\mathrm{PbS})$ thin film having energy band gap of $0.4 \mathrm{eV}$ [3] but Quantum dots (QD) band gap can be varied depending upon temperature and fabrication time [2]. So that by using $\mathrm{PbS} \mathrm{QD}$ it is possible to absorb solar spectrum in visible region.

\subsection{Photo Electrochemical Cell (PEC)}

Fig -1: (a) gives general working principle of PEC. Fig -1: (b) shows work function of materials.
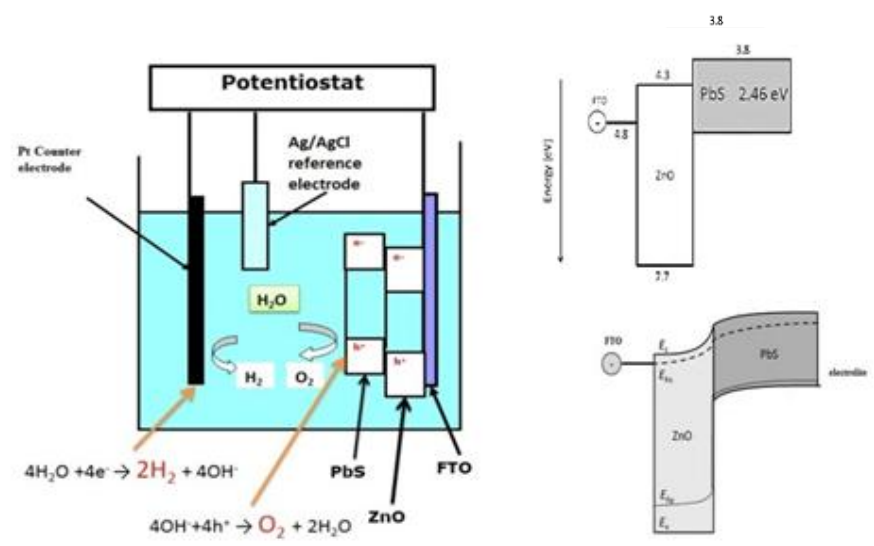

Electron hole pair generates in semiconductor junction which is connected at working electrode. Due to difference in work function of materials, electrons and holes are separated in opposite direction so that recombination can be minimized because of the fact that electrons in conduction band always try to occupy at lower energy state in conduction band and holes in valance band always try to occupy higher energy state in valance band [7]. Generated electrons in semiconductor move to counter electrode through external circuit. Electrons split water molecules while entering into electrolyte from Pt electrode [8].

At Pt/electrolyte junction water splits into

$$
4 \mathrm{H}_{2} \mathrm{O}+4 \mathrm{e}^{-} \leftrightarrow 2 \mathrm{H}_{2}+4 \mathrm{OH}^{-}
$$

At Semiconductor/electrolyte junction

$$
4 \mathrm{OH}^{-}+4 \mathrm{~h}^{+} \leftrightarrow 2 \mathrm{H}_{2} \mathrm{O}+\mathrm{O}_{2}
$$

Diffusion and double layered impedance are formed at semiconductor and electrolyte junction as shown in fig. 2 below. It is distributed impedance, but for simplicity it can be taken as equivalent circuit [9]. This equivalent impedance can be calculated from Electrochemical Impedance Spectroscopy (EIS). Double layered impedance is formed with inner Helmholtz and outer Helmholtz. Helmholtz layer is formed because of $\mathrm{OH}^{-}$ions in solution, consequently positive ions deplete in semiconductor side [4].

Fig- 1: (a) PEC Schematic; (b) FTO/ZnO/PbS work

functions and band bending of semiconductor junction. 


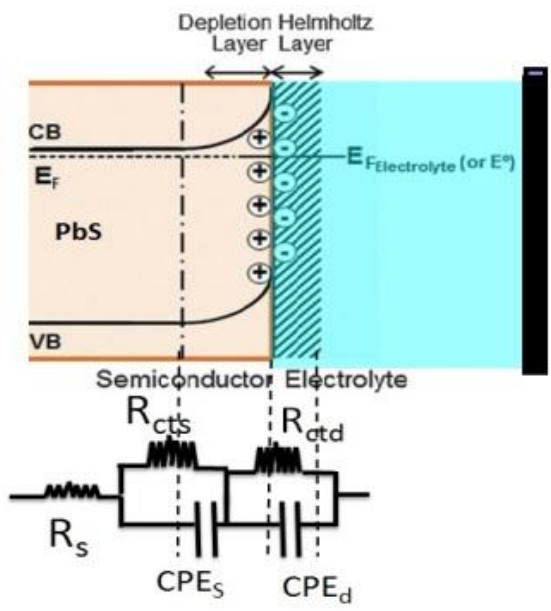

Fig -2: Semiconductor/electrolyte junction Impedance

Here $R_{S}$ is the series resistance of the electrochemical device. $\mathrm{RCT}_{\mathrm{S}}$ and $\mathrm{CPE}_{\mathrm{S}}$ are the charge transfer resistance and capacitance phase element for the depletion layer of the semiconductor. $\mathrm{RCT}_{\mathrm{d}}$ and $\mathrm{CPE}_{\mathrm{d}}$ are the charge transfer resistance and capacitance phase element at the double layer of the semiconductor-electrolyte interface.

\section{EXPERIMENTAL PROCEDURE}

$\mathrm{ZnO}$ nanorods have been prepared in hydrothermal method on Fluorine doped Tin Oxide (FTO) glass. Before that, $\mathrm{ZnO}$ seed layer has been grown to reduce lattice mismatch between $\mathrm{ZnO}$ nanorod and FTO substrate. For seed layer growth, solution was prepared at $65^{\circ} \mathrm{C}$ atmosphere with $0.01 \mathrm{M}$ of Zinc acetate (99\% pure) and Isopropyl alcohol (99\% pure) and homogenized the solution for 30min. 0.02 $\mathrm{M}$ of Di-ethanolamine ( $99 \%$ pure) was added to the same solution. Total solution brought into room temperature and homogenized at the same time until solution turns into Wight transparent solution. A thin, homogenized layer was prepared with this solution by using spin coater at 2000rpm speed. This seed layered samples were heated at $200{ }^{\circ} \mathrm{C}$ for removing the solvents. With this step seed layer growth was completed. Another solution was prepared for growth of $\mathrm{ZnO}$ nanorods with $0.05 \mathrm{M}$ of Zinc Nitrate (98\% pure) and hexamethylenetetramine (HMTA) (99\% pure). This solution was taken in borosilicate glass. Seed layered nanorods were placed in borosilicate glasses with slanting and maintained $95{ }^{0} \mathrm{C}$. While placing sample in borosilicate bottle, it should observe that seed layered side of the FTO glass must face downward. Samples were taken out after 4 hours. This $\mathrm{ZnO}$ nanorod samples were annealed at $350{ }^{\circ} \mathrm{C}$ for 2 hours. With this step $\mathrm{ZnO}$ nanorods preparation was completed. Chemical Bath deposition technique was carried out for preparation of QD thin film on $\mathrm{ZnO}$ nanorods which was followed by J.A. Garcia-Valenzuela et al. [3].

Photoluminescence (PL) measurements were carried out using a He-Cd laser of wavelength $325 \mathrm{~nm}$ and a Triax 310 monochromator. The photo electrochemical characterizations were carried out by three electrode cells using an electrochemical workstation. While testing electrochemical measurements, $\mathrm{ZnO}$ nanorods or $\mathrm{ZnO} / \mathrm{PbS}$ QD were used as working electrode (i.e. photo anode), Pt wire as counter electrode, $\mathrm{Ag} / \mathrm{AgCl}$ as the reference electrode, and $0.1 \mathrm{M} \mathrm{Na}_{2} \mathrm{SO}_{4}$ aqueous solution was used as electrolyte. $\mathrm{Na}_{2} \mathrm{SO}_{4}$ acts as a drying agent so that it forms hydrates at low temperature [10].

\section{RESULTS AND DISCUSSION}

Optical band gap of semiconductors has been calculated from UV-Visible spectroscopy which was done in the range of 300nm to $1000 \mathrm{~nm}$. From Fig. 3(b) \& (c), it was observed that, Energy band gap of $\mathrm{ZnO}$ is $3.237 \mathrm{eV}$, and band gap of $\mathrm{PbS}$ is $2.46 \mathrm{eV}$. So that, $\mathrm{ZnO}$ can absorb solar spectrum at $383 \mathrm{~nm}$, which is in UV region and $\mathrm{PbS}$ can absorb 504nm, which is in Visible region. So that, by taking these two materials in same component, maximum amount of solar spectrum is utilised for generation of more charge carriers.

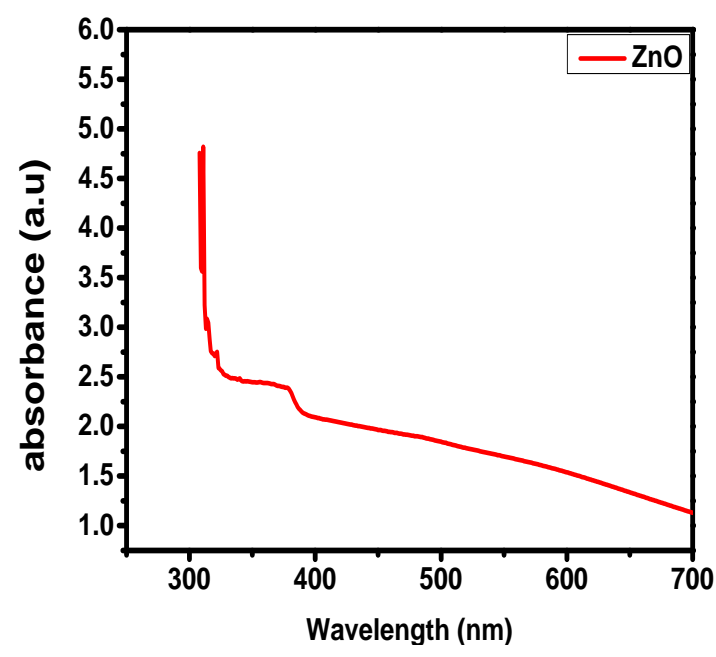

a)

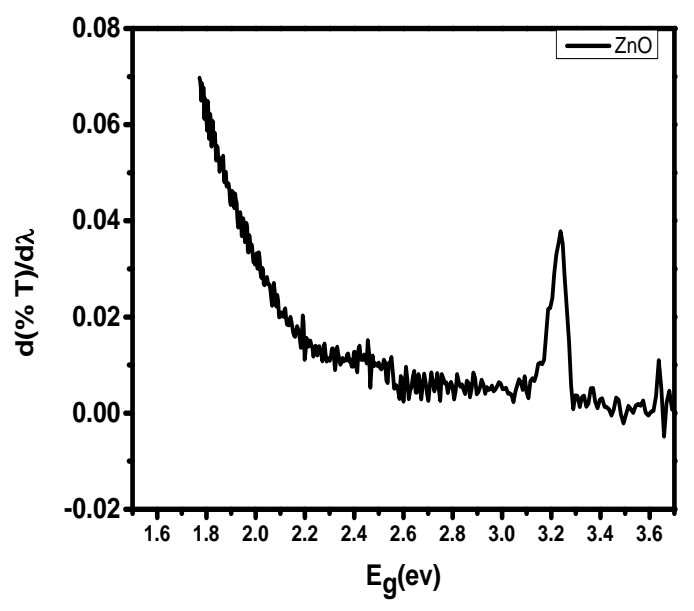

b) 


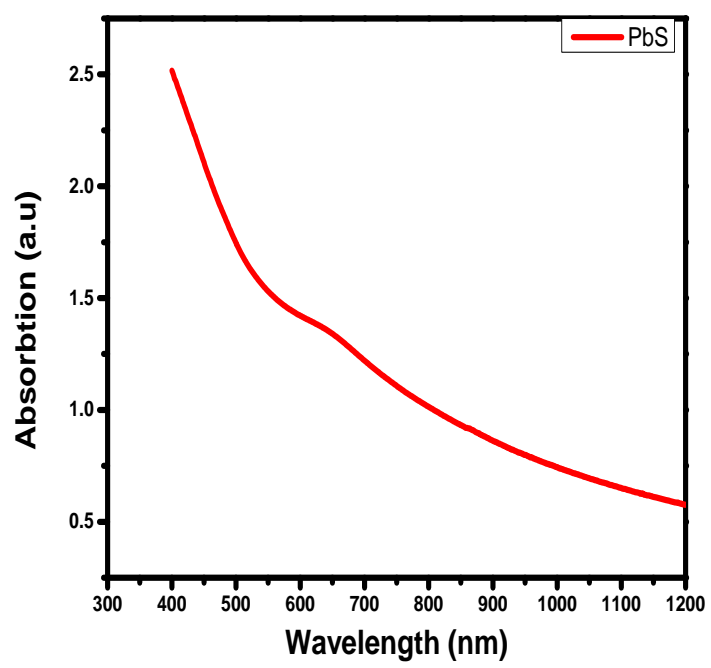

c)

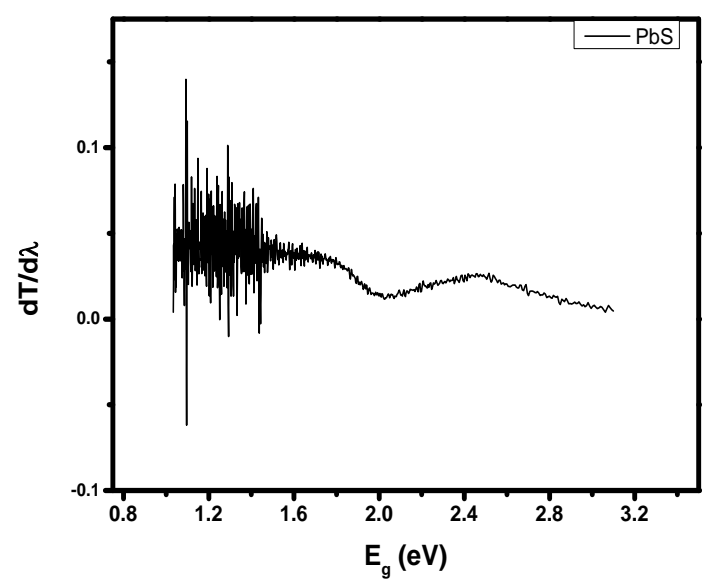

d)

Fig -3: Absorption of (a) $\mathrm{ZnO}$ nanorods, (c) PbS QD thin film, with respect to wavelength. Difference in transmission of (b) $\mathrm{ZnO}$ nanorods, (d) PbS QD thin film w.r.t wavelength to energy bandgap.

Fig -4 shows the plot of $\frac{1}{C^{2}} \mathrm{Vs}$. V for (a) $\mathrm{ZnO}$ nanorods and (b) $\mathrm{ZnO} / \mathrm{PbS} \mathrm{QD}$ thin film, which gives the Mott-Schottky. From the plot extrapolating $1 / \mathrm{C}^{2}$ to zero (i.e. drawing a straight tangential line on to $\mathrm{x}$-axis), the intercept at $\mathrm{x}$-axis gives the flatband potential $\left(\mathrm{V}_{\mathrm{FB}}\right)$. The donor concentrations of $\mathrm{ZnO}$ nanorods and flat band voltage between the nanorods and liquid interface can be estimated using MottSchottky (MS) equation. In flat electrodes, the capacitance of a surface can be written as

$$
\frac{1}{C^{2}}=\frac{2}{e \varepsilon \varepsilon_{0} N_{d} A_{s}^{2}}\left[\left(V-V_{F B}\right)-\frac{K T}{e}\right]
$$

Where, $\varepsilon$ is the dielectric constant of material, $\varepsilon_{0}$ is the permittivity of vacuum, e is the electronic charge, $N_{d}$ is the donor concentration, $\mathrm{V}$ is the applied potential, $\mathrm{V}_{\mathrm{FB}}$ is the flat band potential, $\mathrm{k}$ is the Boltzman constant, As is sample area, and $\mathrm{T}$ is absolute temperature.

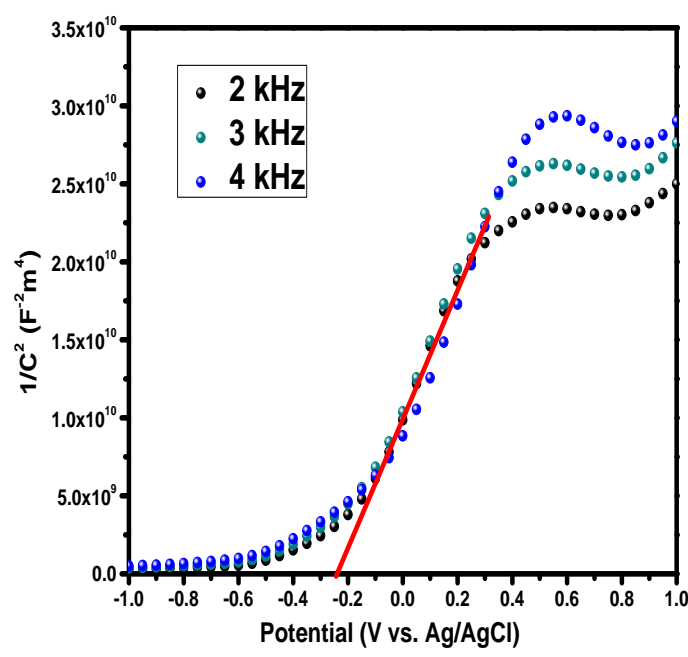

a)

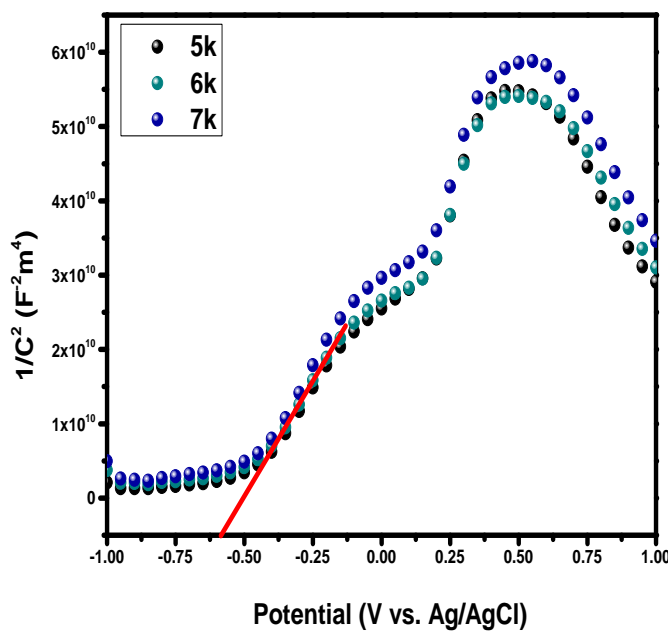

b)

Fig -4: Mott-Schottky plot of (a) ZnO nanorods and (b) $\mathrm{ZnO} / \mathrm{PbS}$ QD thin film.

From the graph flat band potential $\left(\mathrm{V}_{\mathrm{FB}}\right)$ has been found approximately at $-0.247 \mathrm{v}$. Fig $-1(\mathrm{~b})$ gives visualization about flat band bending. As the slope in the linear region of the plot is positive, $\mathrm{ZnO}$ nanorods are n-type in nature [5]. $\mathrm{N}_{\mathrm{d}}=4.21054 \mathrm{E} 18 \mathrm{~cm}^{-3}$ and $\mathrm{W}=2.17857 \mathrm{E}-10 \mathrm{~m}$ at $1 \mathrm{~V}$. In case of $\mathrm{PbS}$, it is also n-type material, flat band potential $\left(\mathrm{V}_{\mathrm{FB}}\right)$ is found to be $-0.5853 \mathrm{~V}, \mathrm{~N}_{\mathrm{d}}=1.261945 \mathrm{E} 18 \mathrm{~cm}^{-3}$ and $\mathrm{W}=4.9853 \mathrm{E}-5 \mathrm{~m}$ at $1 \mathrm{~V}$.

Fig -5 shows impedance at semiconductor/electrolyte junction in Electrochemical Cell. 
a)

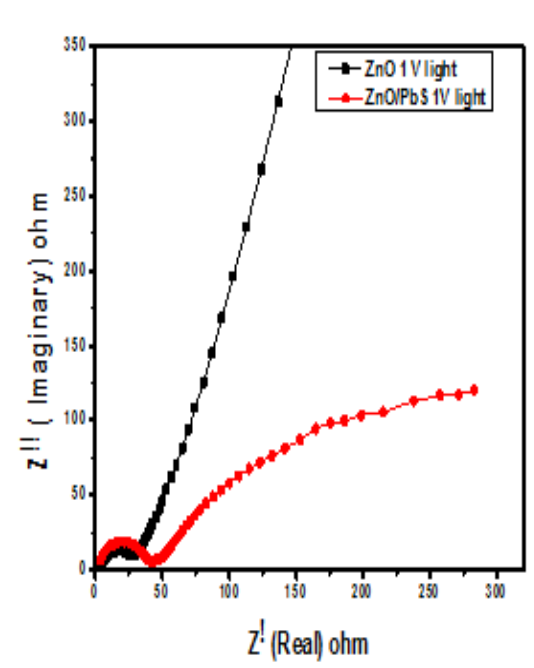

b)

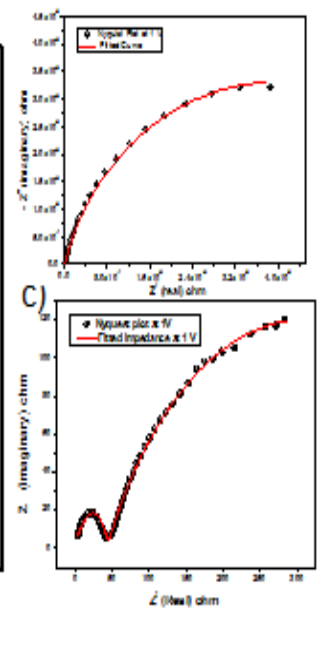

Fig -5: (a) Electrolyte junction impedance of $\mathrm{ZnO}$ and $\mathrm{ZnO} / \mathrm{PbS}$ at $1 \mathrm{~V}$ biasing condition. Fitted curve of Electrolyte junction impedance of (b) $\mathrm{ZnO}$ nanorods and (c) $\mathrm{ZnO} / \mathrm{PbS}$

QD thin film

From Fig -5(a) it is observed that the impedance of $\mathrm{ZnO}$ nanorods is more than that of $\mathrm{ZnO} / \mathrm{PbS} \mathrm{QD}$ thin film. First half circle's diameter which was drawn at high frequency in Nyquist plot shows depletion impedance $\left(\mathrm{RCT}_{\mathrm{s}}\right)$ and second half circle's diameter which was obtained at lower frequency gives double layer impedance $\left(\mathrm{RCT}_{\mathrm{d}}\right)$ value, because charge carriers flow is more in semiconductor region is more than that of electrolyte region [11]. From Fig -5 (b) fitted curves, double layer impedance $\left(\mathrm{RCT}_{\mathrm{d}}\right)$, depletion impedance $\left(\mathrm{RCT}_{\mathrm{s}}\right)$ values of $\mathrm{ZnO}$ are $82 \mathrm{Kohm}$ and 23.5ohm respectively and for $\mathrm{ZnO} / \mathrm{PbS}$ QD thin film is 575 $\mathrm{ohm}$ and $44 \mathrm{ohm}$ respectively. $\mathrm{RCT}_{\mathrm{s}}$ is more in $\mathrm{ZnO} / \mathrm{PbS} \mathrm{QD}$ thin film because of more band bending at the $\mathrm{PbS} /$ electrolyte junction. More the band bending gives more the depletion width. $\mathrm{RCT}_{\mathrm{d}}$ is less because of conduction band of electrolyte is much closer to valence band of $\mathrm{PbS}$ when compared to valance band of $\mathrm{ZnO}$.

\section{CONCLUSION}

$\mathrm{ZnO}$ nanorods and $\mathrm{ZnO} / \mathrm{PbS}$ heterojunction nanorods have been grown on FTO coated glass. Energy bandgap of $\mathrm{ZnO}$ and $\mathrm{PbS}$ materials has been calculated. Flat band voltage, type of the material, majority carrier concentration and depletion width has been calculated from Mott-Schottky. Semiconductor/electrolyte junction impedance values have been observed and compared among them.

\section{REFERENCES}

[1]. Ilya Grinberg, D.V West, M.T, G.U, D.M.T, Liyan W, G.C, E.M.G, A.R.A, P.K.D, J.E.S and A.M. Rappe, Nature, 503, 509-512(2013).

[2]. Ali Hossain Khan, U. Thapakula, Amit.D, S.M, A.D and S. Acharya, J.Phys.Chem. C, 117, 7934-7939(2013).

[3]. J.A. García-Valenzuela, M.R. Baez-Gaxiola, M. SoteloLerma, Thin Solid Films 534 ,126-131(2013).
[4]. Tania Lopes, Luisa Andrade, Helena Aguilar Ribeiro, Adelio Mendes, I.J. Hydro energy, 35,11601(2010).

[5]. T. Majumder, J.J.L. Hmar, K. Debnath, N. Gogurla, J. N. Roy, S. K. Ray, and S.P. Mondal, J. Appl. Phys. 116, 034311 (2014).

[6]. P.V.V Jayaweera, P. K. D. Duleepa P. Pitigala, J.F. Shao, Kirthi T, A.G.U Perera, Pradeep M.J, and Jonas., IEEE, 0018-9383(2010).

[7]. Donald A. Neamen, Semiconductor Physics And Devices (McGrawHill, Int.ed 2003), pp. 349-359. [3 ${ }^{\text {rd }}$ edition]

[8]. Michael Gratzel, Nature, 414, 338-344(2001).

[9]. Juan Bisquert, Ivan M, and Francisco ChemElectro Chem, 00, 1-9(2013).

[10]. John Daintith, The facts on file dictionary of inorganic chemistry (Market House Books Ltd., US , 2004), pp. 210211. [1 $1^{\text {st }}$ edition]

[11]. Tania Lopes, Luisa A, Florian L.F, Michael G, Kevin and Adelio M, Phys. Chem. Chem. Phys.,16, 1651516523(2014).

\section{BIOGRAPHIES}

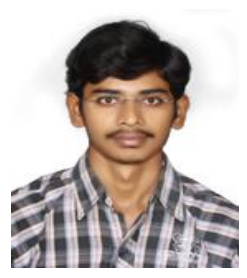

Completed Master of technology from NIT agartala, B.Tech fron JNTUH 